\title{
Espectroscopia em UV-VIS do pireno isolado e em água
}

\author{
Eric Lobato Graef ${ }^{1}$ (IC)*, João Batista Lopes Martins ${ }^{1}$ (PQ) ericgraef90@gmail.com \\ 1 - Instituto de Química, Universidade de Brasília, CP 4478 Brasília, DF, CEP 70919-970, Brasil
}

Ab initio, Espectroscopia, Policíclicos Aromáticos, Pireno, DFT

\section{Introdução:}

Nas ultimas décadas, tem sido estudada a presença de espécies maiores e mais complexas do que se esperava antigamente encontrar no espaço. Aí se encaixa a família dos PAHs (hidrocarboneto policíclicos aromáticos), as maiores moléculas já detectadas nesses ambientes [1].

Muitos estudos foram desenvolvidos com o intuito de identificar esses compostos. A hipótese da presença de tais moléculas em gelos interestelares é um dos focos de estudo.

A espectroscopia do pireno $\left(\mathrm{C}_{16} \mathrm{H}_{10}\right)$, um dos PAHs mais simples, tem sido estudada tanto experimentalmente quanto computacionalmente [2,3], sendo o foco deste projeto de cunho computacional.

\section{Metodologia:}

Foi realizada a otimização da geometria do pireno usando o método TD-DFT com uma vasta gama de funcionais (o espectro de excitação eletrônica foi obtido com esses mesmos cálculos). Todas as otimizações foram feitas em nível TD-DFT. Outras otimizações, ainda com TD-DFT, mas variando o parâmetro ômega do funcional $\omega \mathrm{B} 97 \mathrm{XD}$. Os resultados foram avaliados por NBO.

O pireno foi otimizado embebido por 51 moléculas de água (solvente explícito) usando o método ONIOM, com TD-DFT na camada alta (pireno) e DFT na camada baixa, o funcional usado foi o $\omega \mathrm{B} 97 \mathrm{XD}$, com o parâmetro ômega padrão.

Três das moléculas de água mais próximas do pireno foram selecionadas para cálculos específicos. A interação de cada uma dessas três águas com o pireno foi averiguada a partir de cálculos de NBO.

Todos os cálculos mencionados foram realizados com a função de base def2svp, porém, a influência da base no espectro teórico do pireno isolado foi averiguada com um pequeno número de outras funções de base.

\section{Resultados e Discussão:}

A maioria dos funcionais testados ao fornecer espectros de excitação (TD) inverte a ordenação das duas bandas de menor energia. Apenas dois deles trazem a ordenação correta (Tabela 1). Os espectros na presença de água apresentaram a inversão mesmo com o uso do $\omega \mathrm{B} 97 \mathrm{XD}$.

Verificou-se que a correção de interações a longo alcance associada ao coeficiente ômega é a responsável pela correta ordenação das bandas (pireno isolado). Isso foi confirmado pelos testes com variação de ômega.

Os resultados de NBO explicitam as transferências de população eletrônica que ocorrem nas interações pireno água. Observou-se interações fracas com 
transferência de população eletrônica natural do par isolado do oxigênio para orbitais anti-ligantes de ligações $\mathrm{C}$-H e uma interação com transferência de um orbital ligante C$\mathrm{C}$ para um anti-ligante $\mathrm{O}-\mathrm{H}$.

Tabela 1: Comprimentos de onda correspondentes às bandas de excitação do pireno no UV-VIS, obtidos por TD-DFT. Em vermelho a ordenação invertida das excitações e em azul a ordenação relativa ao experimental.

\begin{tabular}{|c|c|c|c|c|c|c|}
\hline Método: & $\begin{array}{c}\text { Referência } \\
\text { Experimental }\end{array}$ & $\begin{array}{c}\text { CAM- } \\
\text { B3LYP }\end{array}$ & wB97XD & B3LYP & PBE1PBE & B97D \\
\hline$\lambda$ (nm): & 367 & $\mathbf{3 2 8 , 4 9}$ & $\mathbf{3 2 8 , 4 4}$ & 363,02 & 353,56 & 391,49 \\
& {$[4]$} & $(0,0003)$ & $(0,0003)$ & $(0,3218)$ & $(0,3457)$ & $(0,2423)$ \\
\cline { 2 - 7 } & 320 & 321,48 & 321,33 & $\mathbf{3 4 1 , 8 7}$ & $\mathbf{3 3 2 , 8 9}$ & 368,46 \\
& {$[4]$} & $(0,2937)$ & $(0,2990)$ & $(0,0002)$ & $(0,0004)$ & $(0,0001)$ \\
\cline { 2 - 7 } & $\mathbf{2 6 5}$ & $\mathbf{2 5 2 , 2 1}$ & $\mathbf{2 5 1 , 4 0}$ & $\mathbf{2 7 6 , 0 5}$ & $\mathbf{2 6 8 , 0 5}$ & $\mathbf{3 0 2 , 5 0}$ \\
& {$[3]$} & $\mathbf{( 0 , 4 3 4 9 )}$ & $\mathbf{( 0 , 4 4 2 5 )}$ & $\mathbf{( 0 , 2 6 7 1 )}$ & $\mathbf{( 0 , 2 9 1 6 )}$ & $\mathbf{( 0 , 1 8 3 7 )}$ \\
\cline { 2 - 7 } & $\mathbf{2 3 2}$ & $\mathbf{2 2 2 , 3 1}$ & $\mathbf{2 2 1 , 6 3}$ & $\mathbf{2 2 5 , 8 4}$ & $\mathbf{2 1 9 , 9 3}$ & $\mathbf{2 4 4 , 4 0}$ \\
& {$[3]$} & $\mathbf{( 1 , 0 7 0 9 )}$ & $\mathbf{( 1 , 0 7 8 6 )}$ & $\mathbf{( 0 , 5 7 4 5 )}$ & $\mathbf{( 0 , 6 2 9 9 )}$ & $\mathbf{( 0 , 3 7 9 8 )}$ \\
\hline
\end{tabular}

\section{Conclusões:}

Obtiveram-se espectros sem inversão para o pireno isolado usando TD-DFT apenas com dois funcionais específicos, enquanto que os outros geraram espectros com inversão das duas primeiras bandas, que é o resultado mais comum para esse método.

O mesmo não foi possível com solvente explícito, porém as interações pirenoágua puderam ser averiguadas por NBO e os espectros com inversão foram obtidos por TD-DFT.

Foram verificados padrões que podem vir a auxiliar no entendimento das causas da inversão observada. Pretende-se também realizar testes adicionais, com variações nos métodos para obtenção de mais indicativos.

Agradecimentos: FAPDF, CNPq, UnB

\section{Referências}

[1] BOUWMAN, Jordy. Spectroscopy and Chemistry of Interstellar Ice Analogues. $184 \mathrm{f}$. Tese Universiteit Leiden, 2010.

[2] FREIDZON, A. Ya.; VALIEV, R. R.; BEREZHNOY, A. A. Ab initio simulation of pyrene spectra in water matrices. Rsc Adv., 4, 42054-42065, 2014. http://dx.doi.org/10.1039/c4ra05574h.

[3] T. M. Halasinski; F. Salama; L. J. Allamandola. Investigation of the ultraviolet, visible, and nearinfrared absorption spectra of hydrogenated polycyclic aromatic hydrocarbons and their cations. The Astrophysical Journal, 555-566, 2005.

[4] E. A. Mangle and M. R. Topp. Excited-State Dynamics of Jet-Cooled Pyrene and Some Molecular Complexes. J. Phys. Chem. 90, 8021986. 